\title{
Analisis Vegetasi di Sekitar DAS Kali Gendol (Area Bebeng) Taman Nasional Gunung Merapi
}

\author{
Rifka Agnes ${ }^{1)}$,Brilliani O. Amalia ${ }^{1)}$, Rekhisa Kurniawati ${ }^{1)}$, Luthfia P. Amalia ${ }^{1)}$, Larasati N. \\ Ismana $^{1)}$, Istu H. Shafira ${ }^{1)}$ \\ ${ }^{1}$ Pendidikan Biologi, Fakultas Matematika dan Ilmu Pengetahuan Alam, Universitas Negeri \\ Yogyakarta \\ email: larasatinindyaismana@gmail.com
}

\begin{abstract}
Abstrak
TNGM memiliki jenis ekologi yang unik, ekologi di wilayah sekitar gunung merapi seringkali mengalami perubahan ekosistem. Sejalan dengan kedinamisan ekosistem TNGM yang dipaparkan sebelumnya maka vegetasi yang berubah perlu diidentifikasi dan dianalisis untuk mengetahui keanekaragaman dan kondisi ekosistemnya pasca erupsi 2010. Metode pengambilan data pada penelitian ini dilakukan dengan observasi langsung menggunakan pembuatan petak kuadrat, analisis vegetasi, quadrat sampling techniques dan prinsip representative. Analisis data yang digunakan adalah analisis deskriptif hasil observasi. Hasil penelitian ini adalah wilayah observasi memiliki 4 habitus utama yaitu lumut, herba, semak, dan tegakan. Dominansi dengan indeks nilai penting (INP) yang tertinggi pada setiap habitus meliputi Bryopsida sp. dengan INP 300\% untuk lumut, Viburnum sp. deng-an INP 87.43\% untuk herba, Carex sp. dengan INP 132.63\% untuk semak, dan Acacia sp. dengan INP 300\% untuk tegakan. Sedangkan speies dengan dominasi paling rendah pada setiap habitus meliputi Euphorbia sp. dengan INP $8.97 \%$ untuk herba dan Ageratina sp. Dengan INP 37.31\% untuk semak.
\end{abstract}

Kata Kunci-TNGM, Vegetasi, quadrat sampling techniques

\begin{abstract}
TNGM has unique type of ecology, the ecology in the area around Mount Merapi often undergoes ecosystem changes. In line with the dynamics of the TNGM ecosystem described before, changing vegetation needs to be identified and analyzed to find the diversity and condition of the ecosystem after the 2010 eruption. Data collection methods in this study were carried out by direct observation using quadratic plot making, vegetation analysis, quadrat sampling techniques and representative principles. Analysis of the data is descriptive analysis of observations. The results of this study are the observation area has 4 main habitus namely mosses, herbs, shrubs, and stands. Dominance with the highest importance value index (INP) in each habitus includes Bryopsida sp. with $300 \%$ INP for moss, Viburnum sp. with INP $87.43 \%$ for herbs, Carex sp. with INP $132.63 \%$ for shrubs, and Acacia sp. with a 300\% INP for stands. While the species with the lowest dominance in each habitus include Euphorbia sp. with INP $8.97 \%$ for herbs and Ageratina sp. With INP $37.31 \%$ for shrubs.
\end{abstract}

\section{Keywords: TNGM, Vegetation, quadrat sampling techniques}

\section{PENDAHULUAN}

Pada era Revolusi Industri 4.0, perkembangan sains khususnya bidang biologi tidak bisa lepas dari pengaruh perubahan kondisi alam semesta yang bersifat komplementer dan kompreherensif antar peristiwa dalam suatu dimensi ruang dan waktu tertentu. Perkembangan sains yang ada juga sejalan dengan cara pandang dan sikap manusia terhadap alam. Cara pandang yang berbeda di era industri ini seringkali membuat manusia kurang begitu peduli terhadap lingkungan dan terkadang malah ikut berkontribusi dalam merusak lingkungan alam sekitar. Kurangnya kesadaran ini berakibat pada keti-dakseimbangan ekosistem. (Subiantoro \& Handziko, 2011).

Indonesia merupakan salah satu negara yang terletak di daerah tropis, yang memiliki mega biodiversitas dengan keanekaragaman jenis tumbuhan dan hewan yang sangat tinggi (Maharadatunkamsi et al, 2015). Disisi lain berbicara me-ngenai kajian kegunungapian maka salah satu dari pokok pembahasan yang dapat diambil adalah kajian terkait gunung api teraktif di Indonesia yaitu Gunung Merapi. Gunung Merapi memiliki ketinggian 2.968 meter di atas permukaan laut (mdpl). Gunung ini berada dalam wilayah administrasi Kabupaten 
Sleman, Daerah Istimewa Yogyakarta pada lereng selatannya. Kemudian bagian dari Gunung Merapi lainnya berada dalam wilayah Provinsi Jawa Tengah. Gunung merapi memiliki kawasan hutan yang berada di sekitar puncaknya kawasan hutan ini kemudian diresmikan menjadi kawasan Taman Nasional Gunung Merapi sejak tahun 2004. (Purnomo, 2016).

Gunung Merapi termasuk dalam jajaran gunung paling aktif di dunia dengan masa erupsi yang terjadi dalam siklus $4-6$ tahun sekali (Marhaento, 2015). Erupsi Gunung Merapi pada Oktober 2010 tergolong dalam erupsi besar yang pernah terjadi pada Gunung Merapi. Menurut Marhaento (2015) sampai saat ini terdapat 2 erupsi cukup besar dalam kurun waktu 10 tahun yaitu yang terjadi pada tahun 2006, dan puncak-nya pada tahun 2010.

Kawasan Gunung merapi terutama di wilayah sekitar Taman Nasional Gunung Merapi (TNGM) merupakan satu dari banyak kawasan yang terdampak erupsi pada tahun 2010. Erupsi tahun 2010 diperkirakan merupakan siklus ulang 100 tahunan Gunung Merapi. Erupsi besar ini membawa dampak kerugian besar terutama me-nyebabkan kerusakan ekosistem sekitarnya (Muhamad, 2017). Dampak langsung erupsi ini terhadap lingkungan di sekitar Gunung Merapi berupa kerusakan ekosistem yang disebabkan oleh lahar, awan panas dan debu vulkanik dalam jumlah yang sangat besar.

Wilayah TNGM termasuk kedalam wilayah konservasi yang unik karena pada wilayah TNGM ini terdiri dari kombinasi sistem hayati, sistem lanskap dan sistem budaya yang unik. Wi-layah TNGM memiliki hutan tropis pegunungan yang dipengaruhi oleh aktivitas gunung berapi, hal ini ditandai dengan adanya jenis berbagai tumbuhan dan hewan asli Gunung Merapi (Muhamad, 2017). TNGM memiliki Ekosistem hutan yang fungsi sebagai daerah tangkapan air bagi kawasan provinsi Jawa Tengah dan Daerah Isti-mewa Yogyakarta. Fungsi lain dari ekosisten hutan TNGM adalah sebagai tempat ditemukannya berbagai plasma nutfah yang potensial, habitat berbagai flora dan fauna yang dilindungi, serta ikut andil dalam fungsi sosial dan religius (Marhaento, 2015).

Perubahan ekosistem sekitar gunung Merapi meliputi banyak aspek, salah satunya adalah perubahan vegetasi di ekosistemnya. Vegetasi sendiri merupakan kumpulan dari beberapa jenis tumbuhan yang hidup bersama-sama dalam suatu tempat dan terbangun atas unsur- unsur seperti bentuk pertumbuhan, stratifikasi tumbuhan dan penutupan tajuk (Syafei, 1990). Disamping itu, karena adanya perubahan yang dinamis maka perlu adanya analisis vegetasi. Analisis vegetasi sendiri merupakan suatu cara mempelajari kom-posisi dan atau susunan vegetasi dilihat dari segi bentuk (struktur) vegetasi dalam tumbuh-tumbuhan. Hasil yang diperoleh dari analisis ve-getasi ini adalah berupa informasi kuantitatif tentang struktur dan komposisi suatu komunitas tumbuhan (Syafei, 1990). Sejalan dengan kedi-namisan ekosistem TNGM yang dipaparkan sebelumnya maka vegetasi yang berubah perlu diidentifikasi dan dianalisis untuk mengetahui ragam vegetasi pasca erupsi 2010.

\section{METODE PENELITIAN}

Observasi dilakukan pada bulan Oktober 2019 berlokasi di Kawasan Taman Nasional Gunung Merapi, Dusun Kinahrejo, Kecamatan Cangkringan, Kabupaten Sleman, Derah Istimewa Yogyakarta. Lokasi pengamatan berada pada ketinggian 1134 mdpl dengan koordinat 07³4'51,8' lintang selatan dan $110^{\circ} 26^{\prime} 47.3^{\prime \prime}$ bujur timur.

Alat yang digunakan berupa meteran, alat dokumentasi, tali rafia, patok, gunting, dan alat tulis. Metode pengambilan data vegetasi dalam observasi ini menggunakan quadrat sampling techniques dan prinsip representative. Sedangkan, hasil observasi dianalisis menggunakan analisis deskriptif dan analisis vegetasi penghitungan INP serta penghitungan indeks Shannon-Wanon.

\section{HASIL DAN PEMBAHASAN}

Berdasarkan observasi diperoleh hasil bahwa terdapat 313 individu dalam 12 spesies tanaman dari 4 habitus tumbuhan di wilayah TNGM. Berikut merupakan data spesies dan indeks nilai penting (INP) setiap spesies:

Tabel 1.

Data Spesies dan Indeks Nilai Penting Tiap Spesies

\begin{tabular}{lccc}
\hline \multirow{2}{*}{ Nama Organisme } & \multicolumn{3}{c}{ Jumlah (spesies) } \\
& Plot 1 & Plot 2 & INP \\
\hline Bryopsida sp. & 32 & 27 & $300.00 \%$ \\
Helianthus sp. & 15 & 12 & $49.15 \%$ \\
Viburnum sp. & 5 & 9 & $100.96 \%$ \\
Pteridium sp. & 4 & 12 & $63.59 \%$ \\
Nephrolepis sp. & 26 & 0 & $46.68 \%$ \\
Lycopodiella sp. & 8 & 0 & $17.62 \%$ \\
\hline \hline
\end{tabular}




\begin{tabular}{|c|c|c|c|}
\hline \multirow{2}{*}{ Nama Organisme } & \multicolumn{2}{|c|}{ Jumlah (spesies) } & \multirow{2}{*}{ INP } \\
\hline & Plot 1 & Plot 2 & \\
\hline Euphorbia sp. & 0 & 1 & $11.00 \%$ \\
\hline Tiboucina sp. & 1 & 0 & $11.01 \%$ \\
\hline Anthoxantum sp. & 83 & 10 & $130.05 \%$ \\
\hline Ageratina sp. & 15 & 0 & $37.31 \%$ \\
\hline Carex sp. & 30 & 12 & $132.63 \%$ \\
\hline Acacia sp. & 2 & 1 & $300.00 \%$ \\
\hline
\end{tabular}

\section{A. Habitus Tegakan}

Acacia sp dikenal juga dengan nama akasia. Acacia sp. memiliki ciri morfologi antara lain memiliki batang yang berdiri tegak, berkayu ke-ras dengan warna yang bervariasi, antara lain cokelat gelap, cokelat terang hingga krem gelap. Daun tumbuhan akasia memiliki ciri berupa daun berwarna hijau, bagian tepi daun rata, ujung dan pangkal daun berbentuk tumpul, daun tersusun majemuk dengan banyak anak daun yang letak-nya saling berhadapan. Se-lain itu, daun akasia memiliki pertulangan daun menyirip. Panjang daun Acacia sp. sekitar 5-20 $\mathrm{cm}$ dengan lebar 1-2 cm. Pada umumnya Acacia sp. mampu mencapi tinggi lebih dari 15 $\mathrm{m}$, namun pada tempat yang kurang menguntungkan akan tumbuh lebih kecil biasanya antara 7-12 $\mathrm{m}$.

Tumbuhan tegakan yang ditemukan di stasiun 3 hanyalah Acacia sp. Tumbuhan ini tergolong dalam spesies primer dengan indeks nilai penting yang diperoleh sebesar $300 \%$. Tumbuhan ini termasuk pada tumbuhan yang tidak memerlukan persyaratan tumbuh yang tinggi (fast growing). Acacia sp. dapat tumbuh pada kondisi lahan yang sangat ekstrim tingkat kesuburannya, baik kering maupun lembab karena tumbuhan ini tidak begitu terpengaruh oleh jenis tanahnya. Hal tersebut juga karena, Acacia sp. sangat ideal untuk mengantisipasi kondisi ekstrim kering yang mungkin ditimbulkan akibat perubahan iklim (Laksmi et al, 2014). Itulah mengapa Acacia sp. dapat dijumpai pada kawasan suksesi Gu-nung Merapi. Hal ini sesuai dengan kondisi plot yang ada, yaitu daerah hutan yang berbatu dan cukup kering serta banyak ditumbuhi alang-alang.

\section{B. Habitus Lumut}

Bryopsida sp. merupakan vegetasi lumut yang mendominasi pada plot pengamatan dengan jumlah koloni sebanyak 59 dan indeks nilai pentingnya sebesar $300 \%$. Lumut ini termasuk ke dalam jenis lumut daun dengan talus tegak dan lurus sekitar 1-2 $\mathrm{cm}$. Hidupnya mene-mpel pada bebatuan dan berkoloni. Pada plot 1 dan 2 pengamatan, Bryopsida sp. sebagian besar ternaungi oleh tumbuhan lain dan sebagian besar tidak. Pada bagian yang ternaungi jumlah koloninya lebih banyak hal ini karena pada habitat lumut berada di tempat yang lembap dan teduh namun tetap dapat hidup dalam kondisi yang kering (Rost et al., 2006). Lumut merupakan golongan organisme perintis karena dapat tumbuh di tempat tumbuhan tingkat tinggi tidak dapat tum-buh (Gradstein et al., 2001). Oleh karenanya, lumut merupakan organisme yang umum tumbuh pada awal suksesi primer maupun sekunder. Area yang ditumbuhi lumut akan menjadi media yang cocok untuk perkecambahan biji (Glime, 2007).

Karakteristik dari lumut tersebut dapat menjadi alasan mengapa keberadaan lumut mendominasi di wilayah ini. Lumut umumnya hidup di habitat yang lembap dan teduh, tetapi dapat juga toleran terhadap kekeringan, dapat tumbuh pada bermacam substrat seperti tanah, dinding batu, epifit pada tumbuhan lain, bahkan epifit pada jenis lumut lainnya (Rost et al., 2006).

\section{Habitus Herba}

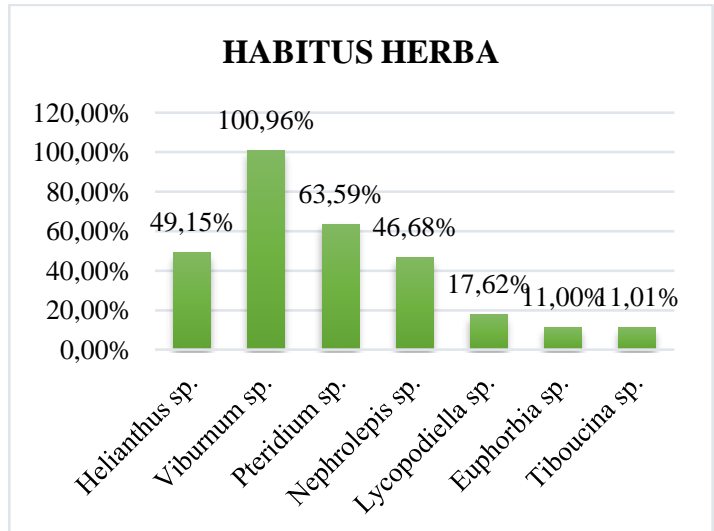

Gambar. 1. Nilai INP Habitus Herba

Nilai INP habitus herba tertinggi adalah Viburnum sp. Sedangkan untuk spesies dengan nilai habitus terendah adalah Euphorbia sp. Sedangkan spesies herba lain yang ditemukan adalah Helianthus sp., Pteridium sp., Nephrolepis sp., Lycopodiella sp., dan Tiboucina sp.

Viburnum sp. merupakan anggota dari keluarga Adoxaceae. Daunnya bersilangan dan bergerigi. Bunganya berukuran $5-15 \mathrm{~cm}$ berwarna putih, krem, ataupun merah muda. Lobus daun memiliki ujung runcing, sedangkan pangkal daun berbentuk bulat. Permukaan atas daun 
Viburnum sp. berwarna hijau sedangkan permukaan bawah daunnya berwarna hijau pucat. Buah Viburnum sp. berbentuk bulat, oval, atau agak rata berwarna merah keunguan, biru atau hitam.

Viburnum sp. merupakan tumbuhan dengan indeks nilai penting tertinggi yaitu sebesar 100,96 \%. Jumlah individu tanaman Viburnum sp. yang ditemukan adalah sebanyak 14 indivi-du. Tum-buhan ini memiliki habitat di hutan pasir berbatu dataran tinggi, hutan berpasir dataran tinggi, bukit pasir stabil dengan vegetasi berkayu, dan lereng hutan berkayu. Oleh karena itu, Viburnum sp. dapat ditemui pada kawasan suksesi Gunung Merapi.

Jumlah individu Euphorbia sp. yang ditemukan memiliki indeks nilai penting $11 \%$. Hal ini menunjukkan bahwa Euphorbia sp. merupakan tumbuhan yang memiliki indeks nilai penting terendah dari seluruh tumbuhan yang berada di kedua plot. Euphorbia sp. ditemukan di plot 2 yang berlokasi di ketinggian 1300 mdpl, Hal ini sesuai dengan penelitian yang ditulis dalam buku oleh Indyo Pratomo, et al. pada tahun 2012 yang menyatakan bahwa ditemukan jenis-jenis dari anggota suku Euphorbiaceae pada ketinggian 1000-1200 mdpl, hal tersebut sesuai dikarenakan ketinggian lokasi tidak jauh berbeda. Plot 2 ber-ada bersebelahan dengan plot 1 , dan kedua plot tersebut merupakan daerah yang kering, namun sebagian besar area pada plot 1 teduh dikarenakan beberapa tumbuhan Acacia sp. tumbuh ditepian plot 1. Euphorbia sp. merupakan tumbuhan herba yang cocok berada pada tanah campuran. Euphorbia sp. mampu hidup dan tumbuh pada daerah yang kering dan minim drainase. Namun, Euphorbia sp. tidak dapat ber-tahan pada kondisi tanah basah atau lembab. Tumbuhan ini juga toleran terhadap cahaya matahari, namun ti-dak seluruhnya teduh. Oleh karena itu, Euphorbia sp. hanya ditemukan di plot 2 karena kondisi plot 1 sebagian besar teduh.

Euphorbia sp. mampu berkembang biak dengan cepat melalui bijinya yang tersebar ke area lain dengan bantuan angin. Kemampuan persebaran biji tumbuhan ini ditunjang dengan berat biji Euphorbia sp. yang ringan. Namun, pada tepian lokasi observasi terdapat beberapa tumbuhan Acacia sp. yang besar dan tinggi sehingga menghalangi angin ke arah kedua plot. Hal tersebut menjadi faktor penghambat lain yang menyebabkan tumbuhan Euphorbia sp. ha-nya ditemukan satu dan hanya berada di plot 2.

D. Habitus Semak

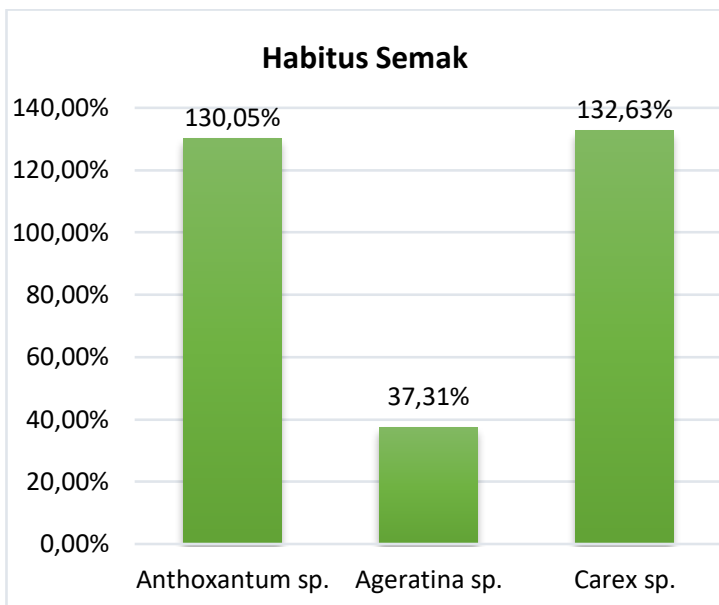

Gambar 2. Nilai INP Habitus Semak

Tumbuhan dengan habitus semak pada stasiun 3 studi lapangan ekologi ditemukan 3 je-nis tanaman, yaitu Anthoxantum sp., Ageratina sp. dan Carex sp., indeks nilai pen-ting tertinggi ada pada tumbuhan Carex sp. dengan nilai indeks penting sebesar $132,63 \%$ sedangkan indeks nilai penting terendah pada tumbuhan Ageratina sp. dengan nilai indeks penting sebesar $37,31 \%$.

Tumbuhan Ageratina sp. memiliki nama lokal babadotan/bandotan/wedhusan karena memiliki aroma khas yang mirip dengan kambing (Mildaerizanti, 2015). Bandotan menyebar luas di seluruh wilayah tropis, bahkan hingga subtropika. Tumbuhan ini berbunga sepanjang tahun dan dapat menghasilkan hingga 40.000 biji per individu tumbuhan. Namun, Ageratina sp. yang ditemukan tidak dapat tumbuh dengan baik karena kondisi lingkungan yang kering dan ku-rang mendukung pertumbuhannya. Hal ini sesuai dengan pernyataan Widyastuti (2017) yang mengatakan bahwa kekeringan menyebabkan banyak biji yang dihasilkan tumbuhan hutan seperti bandotan tidak mampu tumbuh menghasilkan anakan atau tumbuhan baru.

Pada habitus semak indeks penting tertinggi pada Carex sp. yaitu 132,63\%. Carex $s p$. cukup sering dijumpai di sekitar bunker. Menurut Sastrapradja dan Afriastini (1981), jenis semak ini umumnya dijumpai pada tanah kering, berbatu atau berpasir di ketinggian 1.100-3.100 mdpl, hal ini sesuai dengan hasil observasi yang meng-gambarkan bahwa $\mathrm{Ca}$ - 
rex sp. dapat tumbuh dengan baik di wilayah observasi. Carex sp. merupakan tumbuhan yang termasuk dalam famili Cyperaceae, tumbuhan jenis ini menyukai tempat-tempat terbuka. Tumbuhan Carex sp. berperan penting dalam fungsi ekologi baik pada lahan basah maupun lahan kering. Mereka lazim menjadi komunitas yang dominan dalam suatu habitat (Wilson et al., 2014).

\section{E. Indeks Shannon-Wanon}

Berdasarkan data yang diperoleh, selain mendapatkan INP tiap habitus diperoleh juga analisis indeks Shannon-Wanon guna menentukan tingkat keanekaragaman tumbuhan yang ada. Indeks Shannon-Wanon yang diperoleh juga dikategorikan dalam habitusnya. Adapun indeks Shannon-Wanon tiap habitus meliputi lumut, herba, tegakan dan semak berturut-turut adalah sebesar 0.00000 untuk lumut dan tegakan, 0.7340 untuk herba, dan 0.4267 untuk semak. Habitus dengan indeks ShannonWanon 0.00000 menun-jukkan tingkat keanekaragaman yang sangat rendah. Tingkat keanekaragaman naik seiring dengan naiknya nilai indeks Shannon-Wanon.

\section{KESIMPULAN}

Wilayah TNGM yang diobservasi memiliki ragam vegetasi yang cukup kompleks dengan 313 individu dalam 12 spesies tanaman dari 4 habitus. Hasil identifikasi menunjukan 4 habitus utama meliputi lumut, herba, semak, dan tegakan. Indeks nilai penting (INP) yang tertinggi dari tiap habitus adalah sebagai berikut Bryopsida sp. dengan INP 300\% untuk habitus lumut, Acacia sp. dengan INP 300\% untuk habitus tegakan, Carex sp. dengan INP $132.63 \%$ untuk habitus semak, dan Diphasiastrum sp. dengan INP $87.43 \%$ untuk habitus herba. Sedangkan speies dengan dominasi peling rendah dari tiap habitus meliputi Euphorbia $s p$. dengan INP 8.97\% untuk habitus herba dan Ageratina sp. dengan INP $37.31 \%$ untuk habitus semak.

\section{DAFTAR PUSTAKA}

Glime, J.M. (2007). Bryophyte Ecology Vol 1 Physiological Ecology. Michigan: Michigan Technological University.

Gradstein et al. 2001. Guide to the Bryophytes of Tropical America. New York: The New York Botanical Garden Press.
Laksmi Rina, et al. (2014). Budidaya Acacia auriculiformes untuk Kayu Energi. Jakarta: IPB Press.

Maharadatunkamsi, T. Bagus Putra Prakarsa, dan Kurnianingsih. (2015). Struktur Komunitas Mamalia di Cagar Alam Leuweung Sancang, Kabupaten Garut, Jawa Barat. Journal Zoo Indonesia. Vol.24 No 1

Marhaento,H. \& A. N. Kurniab. (2015). Refleksi 5 Tahun Paska Erupsi Gunung Merapi 2010: Menaksir Kerugian Ekologis di Kawasan Taman Nasional Gunung Merapi. Journal of Geomatics and Planning.Vol.2 No.2

Muhamad. (2017). Tapak Ekologi Kepariwisataan Alam pada Zona Pemanfaatan di Taman Nasional Gunung Merapi (TNGM) (Konsep Pengembangan Kepariwisataan Alam Tematik Tapak Kawasan Kalikuning -Kaliadem Sebagai Kawasan Budaya Vulkanik). KAWISTARA Vol. 7 No. 3

Pratomo, Indyo et al. (2012). Ekologi Gunung Slamet: Geologi, Klimatologi, Biodiversitas dan Dinamika Sosial. Jakarta: LIPI Press.

Purnomo, R.P.Sancayaningsih, \& D. Wulansari. (2016). Spesies Tumbuhan Penyusun Vegetasi Lantai Di Wilayah Restorasi Taman Nasional Gunung Merapi Di Ngablak, Magelang, Jawa Tengah. Journal of Tropical Biodiversity and Biotechnology, Volume 1, Issue 2, December 2016, 63-70.

Rost et al. (2006). Plant Biology. London: Wadsworth Publication.

Sastrapradja S, Afriastini JJ. 1981. Rumput pegunungan. Bogor: Lembaga Biologi Nasi-onal, Lembaga Ilmu Pengetahuan Indonesia.

Subiantoro, A. W. \& Handziko,R.C. (2011). Erupsi Merapi dan Potensi Pengembangan Bahan Ajar Biologi Berbasis Representasi. Makalah Seminar Nasional Biologi VIII, Prodi Pend. Biologi FKIP UNS, Tema: "Biologi, Sains, Lingkungan, dan Pembelajarannya menuju Pembangunan Karakter" ISBN: 978-979-1533-23-2.

Syafei, ES. (1990). Pengantar Ekologi Tumbuhan. Bandung. ITB.

Widiyastuti, W et al. (2017).Spesies Tumbuhan Obat di Cagar Alam Sigogor Ponorogo Jawa Timur. E-jurnal Balai Besar Litbang Tanaman Obat dan Obat Tradisional. Vol.10, No. 2 
Wilson., Barbara L., Richard E. B, Danna L., Bruce N., Nick O. (2014). Field Guide to the Sedges of the Pacific Northwest, Second Edition. Oregon State University Press, Corvallis. China.

Mildaerizanti. (2015). Mengenal Babadotan (Ageratum Conyzoides) Sebagai Tumbuhan Sumber Pestisida Nabati Multiguna. Diakses dari http://jambi.litbang.pertanian. go.id/. 